\title{
REFLEXÕES EM TORNO DO PRINCÍPIO REPUBLICANO
}

\author{
Enrique Ricardo Lewandowski
}

\begin{abstract}
Resumo:
O autor enfatiza que no País. quando sc adotou a forma republicana de governo, na verdadi se estava definindo um dos princípios sstruturantes da Lei Maior c a história do principio republicano, desde a Roma Antiga até o republicanismo e a virtude cívica da época contemporânea.
\end{abstract}

Palavras-chave: Res Publica. Res populi. I.iberdade. Igualdade. Legalidade. Eletividade. Temporariedade. Republicanismo.

\begin{abstract}
:
The author emphasizes that. when the republican form of government was adopted in the country, in truth it was defining one of the basal principles of the Constitution and the history of the republican principle, since old Rome until republicanism and the civic virtue of contemporary time.
\end{abstract}

Keywords: Res Publica. Res populi. Liberty. Iguality. Elefivity. Temporariety. Republicanism.

\section{Principio estruturante}

Os constituintes de 1988, não por acaso. adotaram a forma de governo escolhida pelo povo no ano de 1891. em substituição à monarquia, estabelecendo, logo no art. $1^{\circ}$ da Carta Magna, que o Brasil é uma república. Tratou-se de uma opção deliberada e plena de conseqüências, expressamente ratificada pela cidadania no plebiscito realizado em 7 de setembro de 1993, levada a efeito ao mesmo tempo em que definiram que o Estado teria uma configuração federal c adotaria o regime democrático.

A se levar em conta a importância da topologia para a hermenêutica constitucional, não há como deixar de reconhecer que, quando se adotou a forma republicana de governo. na verdade se estava definindo um dos princípios estruturantes de nossa Lei Maior. (Com efcito. o princípio republicano, ao lado dos princípios federativo e democrático, configura, no dizer da doutrina. o "núcleo essencial da Constituição". ' visto que lhe garante uma determinada identidade e estrutura.

Os principios constitucionais, longe de configurarem meras recomendações de caráter moral ou ético, consubstanciam regras jurídicas de caráter prescritivo,

Presidente da Comissão de Publicação da Revista da Faculdade de Dircito da Universidade de São Paulo e Professor Titular de Direito do I:stado da Faculdade de Direito da I niversidade de São Paulo.

CANOTILHO, José Joaquim Gomes. Direito Constituciunal. Cuimbra: Almedina, 1992. p. 349. 
hicrarquicamente superiores às demais e "positivamente vinculantes":- A sua inobservância, ao contrário do que muitos pregavam até recentementc, atribuindo-lhes uma natureza apenas programática deflagra sempre uma consequiência juridica, de maneira compatível com a carga de normatividade que encerram.

Independentemente da preeminência que ostentam no âmbito do sistema ou da abrangência de seu impacto sobre a ordem legal, os principios constitucionais. como se reconhece atualmente, são sempre dotados de eficácia, cuja materialização pode ser cobrada judicialmente se necessário. Sua eficácia, porém, varia segundo o grau de abstração ou generalidade que apresentam, podendo, conformc o caso, atribuir dirctamente a alguém um direito subjetivo, estabclecer um padrão de interprutação a partir de uma hierarquia de valores, autorizar a invalidação de regras ou atos que lhes sejam contrários ou, ainda, impedir a revogação de normas que frustrem a materialização dos fins neles apontados. 3

O princípio republicano, embora de caráter fundamental, apresenta "larga abertura e baixa densidade" " fazendo-se necessário. para conferir-lhe maior concreção. estudá-lo à luz de uma perspectiva histórica, de maneira a identificar suas características essenciais. moldadas ao longo de mais de dois milênios de elaboração doutrinária e prática politica, bem como confrontá-lo com outros princípios e subprincípios que dele decorrem.

\section{Res publica, res populi}

De Roma antiga, onde república identificava algo que a pertencia a todos (res publica) ou ao povo (res populi). até os dias atuais, o conceito sofreu uma longa evolução, embora tenha conservado, em linhas gerais, os fundamentos axiológicos que the deram origem.

Instituída pelos romanos, no inicio do século $\mathrm{V}$ a. ('., a partir da superação da realeza, a república encerra a idéia de coisa comum, de um bem pertencente à coletividade, correspondendo em linhas gerais à antiga noção grega de politeia. regime em que os cidadãos participavam ativamente da gestão da polis. Opõe-se às dcmais formas de

CANOTILHO, José Joaquim (inmes. Direito Constmucional. Coimbra: Almedina, 1992. p. 352.

BARROSO. Luis Roberto. Interpretação e aplicuşũo da Constimição. 6. ed. São Paulo: Saraiva, 2004. p. 377-379.

ESPINDOLA, Rui Samuel. Princípios Constitucionais e Atividade Juridico-Administrativa. In: LEITE, George Salomão (Org̣.). Dos Principios Constitucionais: consideraçōes em tomo das normas principiológicas da Constituição. São Paulo: Malheiros, 2003. p. 265. 
governo, a exemplo da monarquia, na qual se realça o conceito de mando, ou seja, de archia, derivado archein, que significa comandar. chefiar."

Cícero definiu-a como a "cuisu do povo. consideruda tal, não todos os homens de qualquer modo congregados, mus a reuniãu que tem seu fundamento no consentimento juridico e na utilidade comum" "A república, portanto, para o pensador romano, não era uma mera multidão de pessoas rcunidas, sob uma determinada autoridade, mas uma comunidade de interesses organizada, sob a égide da lei.

Maquiavel, embora paradoxalmente tenha defendido o exercício de um poder sem limiles por parte do príncipe, rutomou, séculos depois, o conceito original de república, com base nos clássicos da antigüidade.' Na verdade, não apenas ele, mas também os demais republicanos do cinquecento, para os quais a idéia de liberdade. balizada pela lei comum, constituía um dos eixos em torno qual girava $u$ "humanismo cívico" que praticavam. ${ }^{8}$

Nem sempre. porém, ao longo da História, o termo república teve o mesmo significado. Na Idade Média, as palavras res publica, imperium, regnum e civitas eram empregadas indistintamente para designar aquilo que hoje se entende por Estado (stato), expressão que só se tornou corrente a partir do século XVI. ${ }^{9}$ Mesmo depois de findo o medievo, não se atribuiu à palavra qualquer significado especial, lembrando-se quc Bodin associou-a ao exercício de um poder absoluto e perpétuo, que denominou de "sobcrano" 10

3. Liberdade, igualdade c legalidade

A concepção romana de república foi resgatada, no século XVIII, pur Rousseau, para quem ela correspondia a um "Estado regido pelas leis, qualquer que seja a sua forma de administração" aduzindo que "só então o interesse público governa e u coisa puhlica é alguma coisa" "O pensador genebrino, ademais, desenvolveu a idéia de que as leis procedem da vontade geral, derivada do contrato social, sem conluccer quaisquer restrições (Quidquid populi placuit legis habet vigorem). ${ }^{12}$

5 Cf. verbete "República" In: BOBBIO, Norberto [et al.]. Dicionário de Política. Brasilia: Editora Universidade de Brasília, 1991.

6 De Repuiblica, I, 25.

V. especialmente /l Principe e Discorsi sopra la prima deca di Tirn Livio.

Cf. Newton Bignoto. Maquiavel Republicano. São Paulo, Loyola, 1991, p. 57.

Cf. JELLINEK, Gcorg. Teoria General del Estado. Buenos Aires: Albatros, 1973. p. 99.

Les six livres de la république. I, 8.

"Du Contrat Social, II, 6.

12 Cf. JOUVENEL, Bentrand de. De la souve'rainets: a la recherche du bien politique. Paris: Génin, 1955. p. 216. 
Mas a maior contribuição de Rousseau para o conceito moderno de república foi, sem dúvida, a afìmação da igualdade essencial dos cidadãos, visto que o contrato, sobre o qual se assenta o Estado. coloca todos sob idênticas condições, fazendo com que tenham os mesmos direitos. ${ }^{13}$ Também a liberdade, para o autor, decorre do pacto fundamental, na medida em que somente aos que o integram compete editar normas de convivência social. ${ }^{14}$

Coerentemente com essas idéias, Rousseau concluía que os cidadãos para fazer as leis exprimem sua vontade de forma direta, sem qualquer intermediação, rejcitando, assim, a possibilidade de representação, razão pela qual reduzia os deputados a meros comissários do povo, "que não estão aptos a decidir definitivamente" Is

Kant, seu contemporâneo, embora entendendo também que a res publica latius sic dicta constitui "uma forma de união criada pelo interesse comum de todos os que vivem sob o império da lei" 16 divergia da concepção rousseaniana da participação direta dos cidadãos no governo, explicando que uma verdadeira república "é e não pode deixar de ser um sistema representativo, no qual os direitos do povo são custodiados por deputados que representam a vontade unificada dos cidadãos" 1 ?

\section{Eletividade, temporariedade e responsabilidade}

No Novo Mundo a tese segundo a qual a representação popular configura o cerne de um governo republicano dominou o pensamento político. Madison, cujos escritos. ao lado dos de Hamilton e Jay, contribuíram decisivamente para moldar o arcabouço institucional dos Estados Unidos, assinalava que uma república consiste num "governo que deriva os seus poderes direta ou indiretumente do povo. e é administrado por pessoas que se mantém nos respectivos cargos, por um periodo limitado, ao arbitrio daquele. ou enquanto bem servirem" associando também à noção o princípio da separação dos poderes desenvolvido por Montesquieu como instrumento de contenção do arbitrio dos agentes estatais. ${ }^{18}$

No Brasil, o ideal republicano inspirou, ainda que de forma difusa e inarticulada, grande parte das revoltas e insurreições deflagradas desde os fins do século XVIII e no decorrer da primeira parte da centúria seguinte, que pretendiam instituir governos independentes e republicanos. Mas o ambiente político somente tornou-se

\footnotetext{
Rousscau, op. cit.. loc. cit.

Id., ibid.

Id., III, 6.

Die Methaphysik der Sitten. II, \$43.

7 Id., II. $\$ 52$.

18 The Federalist, 39 \& 47.
} 
propício à derrubada do regime monárquico depois da segunda metade do século XIX, quando "um bando de idéias novas agita o País e dá-lhe novas diretrizes" 19

Com efeito, nessa quadra histórica, o naturalismo. o evolucionismo e o positivismo passaram a influenciar as conviç̧ões da elite pensante, sobretudo dos profissionais liberais e da oficialidade militar, ensejando uma tomada de posição crítica, impregnada de laicismo, com relacão às instituições políticas então vigentes. Por toda a parte cresciam os ataques à monarquia e às suas tradições, em especial ao "poder moderador" prerrogativa constitucional que permitia ao imperador interferir nos demais poderes, tida como a "tirania da Coroa" 20

Deposto D. Pedro Il, em 15 de novembro de 1889, por um golpe militar liderado pelo marechal Deodoro de Fonseca, a imprensa, interpretando o sentimento dos insurgentes c seus adeptos, no mesmo dia registrava que o Brasil, com o fim do ancien régime, ingressou numa nova fase, "passando a regime francamente democrático com todas as consequiencias da liherdade" 21

Os mentores das instituições republicanas no Brasil não alimentavam maiores dúvidas sobre o seu significado. Rui Barbosa, um dos principais artífices da nova ordem. tomando emprestadas as palavras do constitucionalista norte-americano Campell Black, definia a república como um governo "do povo, para o povo c pelo povo" que se apóia na igualdade política dos homens. ${ }^{22}$

Os especialistas contemporâneos não se afastam muito dessc conceito, quando assinalam que "república é o regime politico em que os exercentes das funções politicas (executivas e legislativas) representam o povo e decidem em seu nome, fazendoo com responsabilidade, eletivamente e mediante mandatos renováveis periodicamente" 23 As características essenciais dessa forma de governo são, pois, a eletividade, a temporariedade e a responsabilidade dos governantes.

É interessante reparar que a monarquia, como forma de governo oposta à república, ostenta características diametralmente contrárias, quais sejam, a vitaliciedade. a hereditariedade e a irresponsabilidade. ${ }^{24} \mathrm{Em}$ outras palavras. o monarca governa "enquanto viver ou enquanto tiver condições de governar", procedendo-se à sua escolha

19 COSTA, Cruz. Pequena História da Repúblicu. 3. ed. São Paulo: ('ivilização Brasileira, 1974. p. 25.

20 Id. p. 27.

21 Apud COSTA, Cruz. op. cit, p. 43.

22 PIRES, Homero (Org.). Rui Barbosa: Teoria Política. Rio de Janeiro: Jackson Editores, 1950. p. 48.

23 ATALIBA, Geraldo. Repuiblica e Constituição. São Paulo: Revista dos Tribunais. 1985. p. IX.

24 DALLARI. Dalmo de Abreu. Elementos de Teoria Geral do Fstado. 16. ed. São Paulo,: Saraiva, 1991. p. 191. 
"pela simples verificação da linha de sucessão" não devendo "explicações ao povo ou a qualquer órgão sobre os motivos pelos quais adotou certa orientação politica" 25

Nesse sentido, sob a égide da Constituição, de 1824, a pessoa do imperador era "inviolável e sagrada" em contraste com as cartas republicanas que a ela se seguiram, nas quais, sem exceção, previu-se que o chefe de Ëstado pode perder o mandato pela prática de crime de responsabilidade, sem prejuizo de outras sanções. Essa pena, em nosso ordenamento legal, não ¿ privativa do supremo mandatário da nação, aplicando-se, também, a todos os representantes eleitos, que são afastados das respectivas funções, assim como os demais servidores estatais, consonância com os postulados da accountability e da responsivenes, caso pratiquem atos incompatíveis com o múnus público que lhes ć cometido.

\section{Representação c participação popular}

Numa república os governantes, escolhidos pelo povo, são responsáveis diante dele pela gestão dos negócios públicos. Não exercem o poder por direito próprio, constituindo meros mandatários dos cidadãos. Nessa forma de governo, impera a soberania popular, que encontra expressão por meio de representantes eleitos, distinguindo-se dos regimes despóticos nos quais o povo não tem qualquer ação sobre os governantes, ao mesmo tempo em que se aparta das formas diretas de participação popular, em que os cidadãos governam por si mesmos. ${ }^{26}$

A legitimidade dos representantes do povo radica em eleições que têm como base o sufrágio geral, igual, direto e secreto. que caracteriza, segundo alguns, a própria ratio essendi da república. ${ }^{27}$ Para dar-lhe concreção, impõe-se estender o direito de votar a todos os cidadãos, com exclusão apenas daqueles que não preencham os requisitos da capacidade, vedada qualquer restrição baseada em sexo, raça, rendimento, instrução, ideologia etc.

Fxige-se, por outro lado, que todos os votos tenham a mesma eficácia jurídica, ou seja, o mesmo valor de resultado. O voto há de ter também imediatidade, isto é, deve defluir diretamente da vontade do eleitor, sem intermediação de quem quer que seja e livre de pressões de qualquer espécie. Além disso, o voto pressupõe não apenas a pessoalidade de seu exercício como, também. a ausência de qualquer possibilidade de

ld., ibid.

26 Cf. MAhlberG, Carre de. Contribution a la Theorie Génerate de L'Etat. tomo II. Paris: Sirey, 1922. p. 202.

27 CANOTILHO, José Joaquim Gomes. Direito Constitucional e Teoria da Constituição. 3. ed. Coimbra: Almedina. 1999. p. 159. 
identificação do eleitor. Finalmente o voto precisa ser renovado periodicamente, de modo a assegurar a alternância dos representantes no poder.

O sistema representativo pressupõe ainda a existência de mecanismos que estabeleçam o predomínio da vontade da maioria, com a garantia de que as minorias encontrem expressão no plano político. Para tanto, há que se assegurar não apenas o pluripartidarismo como, também, a mais ampla liberdade de opinião, de reunião e de associação, além de outras franquias pertinentes.

Mas a participação popular atualmente não ocorre mais apenas a partir do indivíduo, do cidadão isolado, ente privilegiado e até endeusado pelas instituições político-jurídicas do liberalismo. O final do século XX e o século XXI certamente entrarão para a História como énocas em que o indivíduo se eclipsa, surgindo em seu lugar as associações, protegidas constitucionalmente, que se multiplicam nas chamadas "organizações não-governamentais"

Esse fato, aliado às deficiências da representação política tradicional, deu origem a alguns institutos, que diminuem a distância entre os cidadãos e o poder, com destaque para o plebiscito, o referendo, a iniciativa legislativa, o veto popular e o recall, dos quais os três primeiros foram incorporados à nossa Constituição (art. 14, I, II e III).

\section{Direitos e deveres}

$\mathrm{Na}$ república romana, os cidadãos de pleno direito (optimo jure), em oposição aos estrangeiros (peregrini), eram detentores de direitos políticos (jura politica), que comprcendiam o voto nos comícios, a clegibilidade para as magistraturas, o acesso ao sacerdócio e faculdade de apelar quando processados. ${ }^{28}$ Também gozavam de direitos civis (jura privata), que incluiam a propriedade, o casamento entre iguais e a possibilidade de demandar na justiça. ${ }^{29}$ Em contrapartida, sujeitavam-se a obrigações (munera). com destaque para o dever de participar do recenseamento (census), de scrvir no exército (militia) e de pagar imposto (tributum). ${ }^{30}$

A idéia moderna de república, a partir da Declaração dos Direitos do Homem e do Cidadão, aprovada pela Assembléia francesa em 1789, encontra-se indissoluvelmente ligada à idéia de que os indivíduos são titulares de direitos em face do Estado, em especial à vida, à liberdade, à propriedade e à participação política. Isso porque, com as revoluções liberais-burguesas, a relação entre governantes e governados

28 LANÇON. Bertrand. O Estado Romano: Catorze séculos de modelos politicos. Sintra: Europa-América, 2003. p. 26.

29 Id., ibid.

30 Id., ibid. 
passou a ser entrevista mais ex parte populi, do ponto de vista dos cidadãos. do que ex parte principis, da perspectiva dos detentores do poder. ${ }^{31}$

Mais tarde, com a Revolução Industrial e as lutas operárias desencadeadas em scu bojo, surgiram os chamados "direitos sociais" tais como o direito ao trabalho, à saúde e à educação, que passaram a intcgrar as constituições promulgadas a partir de então, ao lado dos direitos civis e políticos, que já faziam partı das cartas magnas surgidas em conseqüência da derrocada do absolutismo monárquico, além de uma nova geração de direitos, desenvolvidos em meados do século passado, no contexto de um mundo globalizado, aos quais se denominou de "direitos de solidariedade ou fraternidade" com destaque para a proteção do meio ambiente.

Essas considerações, porém, não arredam a questão básica. sempre recorrente na teoria política, relativa à political obligation, quer dizer, aos deveres dos cidadãos em face do Estado e da sociedade. Com efeito, se as pessoas numa república são titulares de direitos, hão de tur também, em contrapartida, obrigações para com a comunidade, como ocorria em Roma antiga ${ }^{32}$ ou, mais recentemente, na Alemanha, sob a Constituição de Weimar, que enunciava um rol de deveres fundamentais.

Mas ainda que hojc os textos constitucionais, como regra, não façam menção a obrigações, é possível deduzi-los a partir da multisecular tradição republicana, a exemplo do dever de tolerância, de solidariedade. de respeitar os outros, de superar o egoísmo pessoal. de defender a liberdade, de observar os dircitos das pessoas e de servir o bem comum. ${ }^{33}$ São deveres yue Puffendorf. já no século XVII. fazendo eco a conhecida máxima romana, ${ }^{34}$ resumia nos seguintes: "viver em paz e umizade com seus concidadãos; ser cortês e obsequioso; não causar problemas nem criar dificuldudes por obstinução; não desejar ou subtrair a propriedade de outrem" 35

\section{Republicanismo e virtude civica}

Um dos aspectos mais importantes da obra de Maquiavel, e nem sempre bem compreendido, é o destaque que empresta à noção de virtü, inspirada na virtude civica dos antigos romanos (vir virtutis). que não mediam sacrificios em prol do bem

\footnotetext{
31 Cf. BOBBIO, Norberto: VIROLI, Maurizio. Diálogo em torno da Repuiblica: os grandes temas da politica e da cidadania. Rio de Janeiro: ('ampus, 2002. p. 52.

32 Cicero as estuda sistematicamente em seu De Officiis.

33 Cf. BOBBIO, Norberto: VIROI I. Maurizio op. cit., pp. 46-50.

34 Inris praecepta sumt haec: honeste viver: neminem laedere. jus sum cuique lribuer'.

35 PUFENDORF. Samuel. De oficcio hominis el ivis juxta legem naturalem libri duo. $11,18$.
} 
comum. ${ }^{36}$ Para o pensador florentino, os Estados nos quais a virtù declina tornam-se presas fáccis da fortuna, de desfecho incerto, quando as circunstâncias lhes são adversas. ${ }^{37}$

"É. nessa hora" - lembra um intérprete de seu pensamento -. "que as repúblicas, fruto de uma adesão dos homens a um desejo de liberdade e às instituições yue as exprimem, revelam-se muito mais fortes para resistir aos ataques do tempo" 38 Isso porque. sem cidadãos "capazes de resistir contra os arrogantes, servir ao bem público, a república morre, torna-se um lugar em que ulguns dominum e outros servem" :i9

Atualmente, a virtude cívica, como já se afirmou, constitui uma característica dos homens e mulheres que "desejam viver com dignidade e, porque sabem que não podem viver com dignidade em uma comunidade corrupta, fazem o que podem, quando podem, para servir à liberdade comum" levando-os a repudiar a prevaricação, a discriminação, a corrupção, a arrogância e a vulgaridade. ${ }^{40}$

Alguns agem estimulados por um senso moral mais desenvolvido ou por um sentimento de decência e decoro mais aguçado, outros se vêem impelidos por uma série de interesses legítimos. outros ainda encontram motivação no desejo de obter a estima ou o reconhecimento social, não sendo raro que tais razões atuem de forma combinada. reforçando-se reciprocamente. ${ }^{41}$

\section{República e Constituição}

O princípio republicano, entre nós, representa a viga mestra do "sentimento constitucional" (Verfassungsgefüll) a que se refere a doutrina alemã, ou seja, de um estado de espírito coletivo que, "transcendendo todos os antagonismos e tensões existentes, politico-partidárias, econômico-sociais, religiosas ou de outro tipo, integra os detentores e destinatários do poder num marco de uma ordem comunitária obrigatória" 42

A Constituição, de 1988, com o seu núcleo republicano. derivou de um sentimento de repulsa ao regime de exceção imposto pclos governos militares, bem como de repúdio ao passado histórico de autoritarismo político c de exclusão social, consubstanciando um projeto de desenvolvimento nacional que busca a superação das desigualdades, a efetivação dos direitos fundamentais e a consolidação da democracia.

\footnotetext{
36 Cf. especialmente II Principe, XXV e XXVI.

$37 \mathrm{Cf}$. BIGNOTO, Newton op. cit., p. 152.

38 Id., ibid.

39 BOBBIO, Norberto; VIROLI, Maurizio. op.cit., p.l6.

40 Op. cit.. p. 17.

4 Id., ibid.

42 LOEWENSTEIN, Karl. Teoria de la Constifución. 2. ed. Barcelona: Editorial Ariel, 1976. p. 200.
} 
Por essa razão, o principio republicano, na sistemática constitucional vigente, não se resume apenas à eleição dos representantes do povo, por um mandato renovável periodicamente (arts. $27, \S 1^{\circ} ; 28 ; 29,1$ e II: e 82). mas implica também a igualdade de acesso dos cidadãos aos cargos públicos, eletivus ou-não, preenchidos os requisitos legais (arts. $14, \S 3^{\circ}$; e 37,1 ), além de contemplar a progressiva superação das causas da pobreza e dos fatores de marginalização, simultaneamente à supressão dos privilégios de todo o gêncro (arts. $1^{\circ}$ I e II; $3^{\circ}$ I III e IV; $5^{n} ; 6^{\circ} ; 7^{\circ} ; 23, \mathrm{X}$; e 170, VII).

Mas ao lado dessas franquias, o constituinte criou também mecanismos de defesa que protegem as instituições contra ataques potencialmente destrutivos, estabelecendo condições e restrições ao exercicio da cidadania, que limitam ou até mesmo suprimem o direito do cidadão de participar do processo elcitoral ou de exercer funções públicas. Nesse sentido, para que alguém concorra a um cargo eletivo, é preciso que, de um lado, satisfaça as condições de elegibilidade e, de outro, não incorra nas causas de inelegibilidade, listadas no próprio texto constitucional, com o escopo de proteger a probidade administrativa e a moralidade para o exercício do mandato (art. 14, §9).

A Constituição vinculou ainda a atuação dos servidores do Estado à observância dos cânones da legalidade, impessoalidade, moralidade, publicidade c eficiência (art. 37), significando que devem exercer suas funções, de forma lícita, imparcial, produtiva e transparente, visando exclusivamente ao interesse público e não à satisfação de desígnios particulares. Em defesa desses postulados estabeleceu que a prática de atos de improbidade administrativa importa a suspensão dos direitos políticos, a perda da função pública, a indisponibilidade dos bens e o ressarcimento ao erário, nos termos da lei (art. 15, V; e 37, $\S 4^{\circ}$ ).

Ademais, atribuiu a qualquer cidadão o direito de ajuizar ação popular para anular ato lesivo ao patrimônio público, à moralidadc administrativa, ao meio ambiente e ao patrimônio histórico e cultural (art. $5^{\circ}$, LXXIII) -- âmbito de interesses correspondente hoje à esfera de valores compriendida pela res publica dos antigos romanos --, tarefa também cometida supletivamente ao Parquet (art.129, II), cujas funções institucionais foram sobremaneira ampliadas pelo legislador constitucional.

Por fim, cumpre notar que, se todo princípio constitui um "mandamento de otimização", ou seja, um preceito que determina "que algo seja realizado na maior. medida possivel, dentro das possibilidades juridicas e fáticas existentes" 43 forçoso é concluir que o princípio republicano, enquanto complexo axiológico-normativo situado no ápice de nossa hierarquia constitucional. deve ser expandido em sua extensão máxima.

43 ALEXY, Robert. Teoria de los Derechos Fundamentales. Madrid: Centro de Estudios Politicos y Constitucionales. 2002. p. 86. 
afastando nesse processo todas os princípios, regras e atos que the sejam contrários. Convém lımbrar, todavia, que a força imperativa desse princípio será tanto maior quanto mais elevado for o grau de mituridade cívica dos cidadãos e quanto mais conscientes estejam de que são titulares não-só de direitos mas também de deveres em face da coletividade.

São Paulo, dezembro de 2005.

Referências

ALFXY, Robert. Tioria de los Derechos Fundamentales. Madrid: Centro de Estudios Políticos y Constitucionales, 2002.

ATAliBA, Geraldo. República e Constituição. São Paulo: Revista dos Tribunais, 1985.

BARROSO, Iuis Roberto. Interpretação e aplicação da Constituição. 6. ed. São Paulo: Saraiva. 2004.

BIGNOTO, Newton. Muquiavel Republicano. São Paulo: Loyola, 1991.

BOBBIO, Norberto; VIROLI, Maurizio. Diálogo em torno da Répuiblica: os grandes temas da política e da cidadania. Rio de Janeiro, Campus, 2002.

CANOTIl.hO, José Joaquim Gomes. Dircito Constitucional e Teoria da Constituiçãu. 3. ed. Coimbra: Almedina, 1999.

CANOTII.HO, José Joaquim Gomes. Direito Constitucional. Coimbra: Almedina, 1992.

COSTA, Cruz. Pequena História da República. 3. ed. São Paulo: Civilização Brasileira. 1974.

DAI LARI, Dalmo de Abreu. Elımentos de Teoria Geral do Estado. 16. ed. São Paulo: Saraiva, 1991.

ESPINDOLA, Rui Samuel. Princípios Constitucionais e Atividade Jurídico-Administrativa. In: LEITE, George Salomão (Org.). Dos Principios Constitucionuis: Considerações em torno das normas principiológicas da Constituição. São Paulo: Malheiros, 2003. p. 265.

JELLINEK, Georg. Tenria General del Estado. Buenos Aires: Albatros, 1973.

JOUVENEL, Bertrand de. De la souveraineté: a la recherche du bien politique. Paris: Génin, 1955.

LANÇON, Bertrand. U Fstado Romano: Catorzc séculos de modelos políticos. Sintra: EuropaAmérica, 2003. 
LOEWENSTEIN, Karl. Teoria de la Constitución. 2. ed. Barcelona: Lditorial Ariel, 1976.

MAHLBERG, Carré de. Contribution a la Theorie Génerale de l. 'Étal. tomo II. Paris: Sirey, 1922.

PIRES, Homero (Org.). Rui Barbosa: Teoria Política. Rio de Janeiro: Jackson Editores, 1950.

PUFENDORF, Samuel. De oficcio hominis st civis juxta legem naturalcm libri duo, II, 18.

REPÚblCA. In: BOBBIO, Norberto [et al.|. Dicionário de Política. Brasilia: Editora Universidade de Brasilia, 1991. 